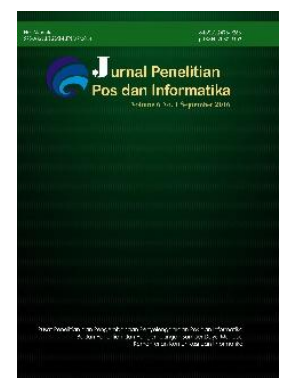

JPPI Vol 5 No 2 (2015) 175 - 190

Jurnal Penelitian Pos dan Informatika

578/AKRED/P2MI-LIPI/07/2014

e-ISSN: 2476-9266

p-ISSN: 2088-9402

DOI: $10.17933 /$ jppi.2015.0502004

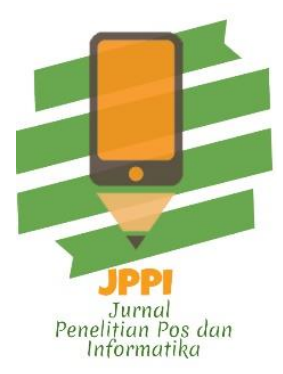

\title{
KAJIAN LITERATUR SINKRONISASI WAKTU DENGAN NETWORK TIME PROTOCOL UNTUK PEMANTAUAN AKTIVITAS JARINGAN TELEKOMUNIKASI
}

\section{LITERATURE STUDY OF TIME SYNCHRONIZATION USING NETWORK TIME PROTOCOL FOR TELECOMMUNICATION NETWORK SECURITY MONITORING}

\author{
Ahmad Budi Setiawan \\ Puslitbang Aplikasi Informatika dan Informasi Komunikasi Publik, Kementerian Kominfo \\ J1. Medan Merdeka No.9, Jakarta,10110, Indonesia \\ ahma003@kominfo.go.id
}

Naskah diterima : 24 Agustus 2015; Direvisi : 10 November 2015; Disetujui : 16 November 2015

\begin{abstract}
Abstrak
Penyelenggara Jaringan adalah menyediakan dan atau memberikan pelayanan jaringan yang memungkinkan terselenggaranya transaksi elektronik. Setiap penyelenggara jaringan diwajibkan untuk menyelaraskan waktu dalam transaksi elektronik. Tujuan dilakukannya penyelarasan waktu adalah untuk menyediakan waktu yang standar dan menyediakan acuan waktu untuk segala bentuk transaksi elektronik dengan prinsip keakuratan dan ketertelusuran. Sistem Penyelarasan Waktu Indonesia menggunakan prinsip ketertelusuran dan prinsip keakuratan. Protokol yang digunakan dalam penyelarasan waktu server di Indonesia berbasis Network Time Protocol. Kajian ini membahas mengenai implementasi sinkronisasi waktu dengan network time protocol sebagai salah satu bentuk pemantauan keamanan jaringan telekomunikasi. Metode yang digunakan dalam kajian ini adalah naratif deskriptif mengenai implementasi sinkronisasi waktu.Hasil kajian ini adalah masukan untuk kebijakan dalam keamanan transaksi elektronik melalui sinkronisasi waktu.
\end{abstract}

Kata Kunci : sinkronisasi waktu, keamanan jaringan, transaksi elektronik, protocol waktu jaringan

\begin{abstract}
Network providers are providing services or networks that enable the implementation of electronic transactions. Each network operator is required to align the time in electronic transactions. The purpose is to provide time alignment of the time standard and provide a time frame for all forms of electronic transactions with the principles of accuracy and traceability. Indonesian Time Alignment System uses the principle of traceability and accuracy principles. The protocols used in the alignment of the time server in Indonesia-based Network Time Protocol. This study discusses the implementation of time synchronization with a network time protocol as a form of telecommunications network security monitoring. The method used in this study is a descriptive narrative on the implementation of time synchronization. Results of this study are input to the policy in the security of electronic transactions through time synchronization
\end{abstract}

Keywords : time synchronization, network security, electronic transaction, network time protocol 


\section{PENDAHULUAN}

Dalam system transaksi elektronik dan teknis telekomunikasi, sangat diperlukan keselarasan waktu antar pihak yang saling terkait. hal ini dibutuhkan untuk menghindari kerugian yang ditimbulkan dengan adanya ketidakselarasan waktu. Disamping itu, waktu juga dapat digunakan sebagai bukti untuk menelusuri kejadian jika terjadi suatu fraud atau pelanggaran dan kecurangan dalam bertransaksi menggunakan system elektronik.

Sesuai dengan Peraturan Menteri Kominfo Nomor 27/PER/M.KOMINFO/9/2006 Tentang Pengamanan Pemanfaatan Jaringan Telekomunikasi Berbasis Protokol Internet. Berdasarkan Peraturan Menteri tersebut, setiap penyelenggara jaringan telekomunikasi diwajibkan untuk memantauan aktivitas telekomunikasi/internet (monitoring), merekam catatan transaksi koneksi (log), dan mensinkronisasikan waktu (NTP) [1] Penyelenggara jaringan dan jasa telekomunikasi tersebut antara lain; Operator (Penyelenggara Infrastruktur), Penyelenggara Network Access Point (NAP), Penyelenggara Exchange Point (IXP), Penyelenggara Jasa Internet (ISP). Berdasarkan Undang-Undang No. 11 Tahun 2008 tentang Informasi dan Transaksi Elektronik (UU ITE) [2] dan Peraturan Pemerintah No 82 Tahun 2012 tentang Penyelenggara Sistem Transaksi Elektronik (PP PSTE), penyelenggara jaringan dan jasa telekomunikasi juga merupakan penyelenggara system elektronik yang memfasilitasi transaksi elektronik [3].

Terkait dengan sinkronisasi waktu, hal ini menjadi sangat penting dalam transaksi elektronik dan telekomunikasi Karena banyak peralatan elektronik sangat membutuhkan penggunaan waktu yang standar atau sama. Sampai kini dikenal banyak cara untuk mendapatkan keseragaman waktu. Salah satunya dengan cara paling umum, dengan menggunakan metode pedoman Greenwich Meridien Time (GMT).

Untuk menghitung waktu jeda itu, dibuat jam atom. Harapannya agar ditemukan cara lebih akurat, dalam menghitung waktu perputaran bumi. Pada penelitian jam atom yang dilakukan Tom Parker dari National Institute of Standard and Technology (NIST) yang bermarkas di Boulder, Colorado. Jam ini merupakan sebuah tabung tembaga vertikal berukuran beberapa meter yang diselubungi lapisan tipis sebagai pelindung dari unsur magnetik bumi. Tabung ini dikelilingi enam lapisan. Empat lapis terletak di bagian kanan, satu lapis berada di puncak dan bawah. Bagian atas tabung dilingkupi oleh pemancar gelombang mikro. Di bawahnya, terdapat sebuah detektor cahaya.

Alat pengukur ketepatan waktu alias chronometer ini diberi nama f-1 Cesium Fountain Atomic Clock, merupakan pusat jam dunia. Sebagai perbandingan, jam atom ini bekerja sama dengan jam serupa yang ada di Paris. Keduanya saling menciptakan sinkronisasi yang ditiru oleh semua jam di dunia dengan mengetahui panjang detik seakurat dengan bagaimana dunia masa kini berputar. Saat ini, teknologi yang digunakan adalah penyebaran tanda waktu melalui jaringan internet, menggunakan standar komunikasi yang disebut NTP (Network Time Protocol). Standar NTP memungkinkan sinkronisasi waktu secara tepat dan presisi, dengan perangkat-perangkat yang sudah umum digunakan seperti komputer dan telepon pintar atau smartphone. "Sistem tersebut sudah memperhitungkan delay dalam proses transmisi, sehingga ketepatannya dapat dijamin di mana pun 
ada koneksi ke jaringan internet," katanya.

Sinkronisasi waktu sangat penting untuk sensor jaringan telekomunikasi pada layer-layer disetiap desainnya. Hal ini memungkinkan siklus kerja radio, pelokalan yang akurat dan aman, dan pemrosesan sinyal kolaboratif lainnya yang lebih baik. Meskipun demikian, sinkronisasi waktu memiliki permasalah tersendiri dan telah diteliti secara mendalam dalam sensor jaringan. Kebutuhan akan sinkronisasi waktu ini merupakan sebuah solusi atas permasalahan dalam transaksi elektronik yang mengemuka, aspek keamanan jaringan [4]. Terkait hal tesebut, ada beberapa implementasi prototipe, seperti akurasi RBS [5], TPSN [6], FTSP [7], LTS [8], Mini/Tiny Sync [9] yang dapat mencapai mikrodetik.

Sistem elektronik sangat membutuhkan penggunaan waktu yang standar atau sama, misalnya untuk sistem komputasi awan, sistem komputer terdistribusi, sistem keamanan informasi, sistem penerbangan, sistem perbankan atau transaksi elektronik, dan lain-lain. Sejak era internet, tersedia perangkat server waktu di internet yang dapat digunakan sebagai acuan bagi komputer atau perangkat elektronik yang terhubung ke internet. Ketidakragaman waktu membuat banyak peluang bisa hilang. Kerugian saat bertransaksi elektronik, tertinggal pesawat, atau rugi saat telat menyetor kliring perbankan merupakan beberapa contoh akibat ketidakberagaman waktu tersebut.

Sebagai ilustrasi, berikut ini adalah contoh kerugian yang dapat ditimbulkan pembelian saham yang disepakati pada waktu tertentu. Misal perusahaan A membeli saham Perusahaan B melalui pasar saham. Waktu transaksi disepakati pada pukul 09:00:00 WIB, dengan harga saham sesuai harga pasar pada pukul 09:00:00 WIB tersebut.
Jika acuan waktu yang digunakan oleh perusahaan A dan B tidak sama, maka akan timbul masalah.

Contoh lainnya dalam hal mekanisme pembayaran on-line; Pembayaran tagihan hutang dengan batas waktu (deadline) tertentu. Misal perusahaan $\mathrm{C}$ membuat kesepakatan hutang-piutang dengan perusahaan D. Pembayaran tagihan dengan batas waktu paling lambat tanggal 1 Oktober 2013 pukul 12:00:00 WIT. Jika acuan waktu yang digunakan perusahaan $\mathrm{C}$ dan $\mathrm{D}$ tidak sama, maka akan timbul masalah. Dua hal yang menjadi perhatian utama dalam menentukan acuan waktu dan sinkronisasi waktu adalah keakuratan dan ketertelusuran.

Pentingnya sinkronisasi waktu pada penyelenggara jaringan telekomunikasi untuk menjamin keamanan transaksi elektronik perlu ditindaklanjuti dengan implementasi, maka perlu sebuah rujukan penyelarasan waktu tunggal. Implementasi sinkronisasi waktu dalam transaksi elektronik merupakan kewajiban bagi seluruh penyelenggara jaringan dan jasa telekomunikasi. Dengan demikian dibutuhkan integrasi desain, teknologi dan infrastruktur rujukan serta efisiensi untuk mencegah duplikasi dan tumpang tindih. Hal ini juga bertujuan untuk mempermudah pengelolaan dan pengawasan. Disamping itu, standarisasi format pewaktuan internasional untuk penegakan hukum menghindari perbedaan persepsi. Kajian ini membahas bagimana implementasi sinkronisasi waktu dengan NTP untuk pemantauan keamanan transaksi elektronik pada penyelenggara jarinan telekomunikasi. 


\section{METODE}

NTP Server atau Time Server dapat berupa komputer biasa yang dijadikan server waktu. Network Time Protocol atau lebih sering disebut dengan istilah NTP merupakan sebuah mekanisme atau protokol yang digunakan untuk melakukan sinkronisasi terhadap penunjuk waktu dalam sebuah sistem komputer dan jaringan. Proses sinkronisasi ini dilakukan di dalam jalur komunikasi data yang biasanya menggunakan protokol komunikasi TCP/IP. Sehingga proses ini sendiri dapat dilihat sebagai proses komunikasi data biasa yang hanya melakukan pertukaran paket-paket data saja.

Acuan waktu paling dasar (Stratum 0) yang terhubung ke NTP Server berupa peralatan khusus atau komputer khusus yang bekerja sebagai penyedia waktu acuan, misalnya jam atom. Jam acuan pada Stratum 0 ini tidak tersambung ke jaringan. NTP Server memiliki beberapa tingkatan. Gambar 1 berikut ini menunjukkan perangkat/komputer jam acuan (Stratum 0) terhubung ke salah satu komputer server di tingkat bawahnya atau Stratum 1. Server Stratum 1 saling terhubung melalui jaringan dengan Stratum 1 lainnya dan Stratum 2. Server-server Stratum 2 juga saling terhubung melalui jaringan, dan terhubung ke Stratum 3, dan seterusnya.

Sesuai informasi yang tersedia di ntp.org, contoh Stratum 1 Time Server adalah ntp.amnic.net. Contoh Stratum 2 Time Server adalah ntp.adc.am. Sedangkan contoh NTP Pool Time Server adalah pool.ntp.org, asia.pool.ntp.org, europe.pool.ntp.org, dan lain-lain.
NTP merupakan protokol yang implementasi softwarenya untuk sinkronisasi jam sistem komputer melalui paket-switched, jaringan data variabel-latency. NTP ini didasari pada GMT dengan menggunakan algoritma Marzullo. NTP menggunakan hirarki yaitu sistem semi-berlapis pada tingkat sumber waktu. Maka, setiap tingkat hirarki ini disebut suatu stratum dan diberikan nomor lapisan dimulai dengan 0 (nol), 1 (satu) dan seterusnya.

1. Stratum 0, merupakan perangkat seperti atom (caesium, rubidium) jam, jam GPS atau jam radio. Perangkat Stratum 0 secara tradisional tidak melekat pada jaringan, melainkan mereka secara lokal terhubung ke computer.

2. Stratum 1, merupakan komputer yang melekat pada perangkat Stratum 0 . Biasanya mereka bertindak sebagai server untuk permintaan waktu dari server Stratum 2 melalui NTP .

3. Stratum 2, merupakan komputer yang mengirimkan permintaan NTP untuk server Stratum 1. Biasanya komputer Stratum 2 akan mereferensikan sebuah angka dari server Stratum 1 dan menggunakan algoritma NTP untuk mengumpulkan sampel data terbaik.

4. Stratum 3, merupakan komputer-komputer ini menggunakan fungsi yang sama persis NTP dan mereka sendiri dapat bertindak sebagai server untuk strata yang lebih rendah. 


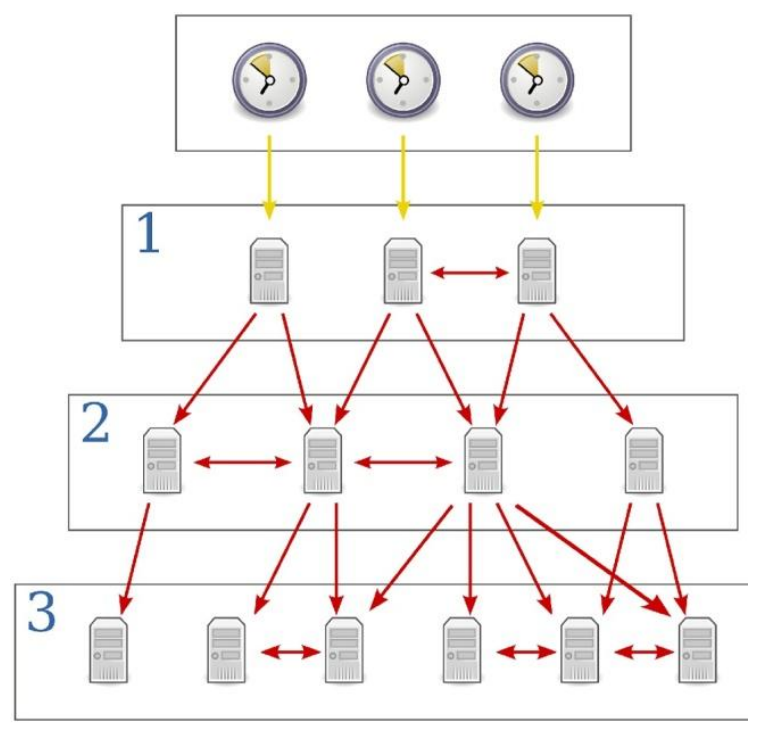

Gambar 1. Cara kerja sinkronisasi waktu

Setiap NTP mulai memeriksa file konfigurasi ( / etc / ntp.conf) untuk menentukan sumber syncronization, pilihan otentikasi, pilihan pemantauan, kontrol akses dan pilihan operasi lainnya. Setelah daemon NTP aktif dan running, NTP akan beroperasi dengan pertukaran paket dengan server yang dikonfigurasi pada interval polling dan perilakunya akan tergantung pada penundaan antara waktu lokal dan server referensi. Pertukaran paket berlangsung sampai server NTP diterima sebagai sumber sinkronisasi, yang memakan waktu sekitar lima menit. NTP daemon mencoba untuk mengatur jam dalam langkahlangkah kecil dan akan berlanjut sampai klien mendapatkan waktu yang akurat. Jika penundaan antara server dan klien cukup besar maka daemon akan menghentikan nya secara otomatis.

Rincian operasional NTP yang ditetapkan dalam RFC 778, RFC 891, RFC 956, dan RFC 1305. Pelaksanaan rujukan saat ini adalah versi 4 (NTPv4); Namun, pada 2005, hanya versi hingga 3 (1992) telah didokumentasikan dalam RFC. The Internet Engineering Task Force NTP Working Group merupakan standardisasi karya komunitas NTP sejak penerbitan RFC 1305
Sementara itu, Metode yang digunakan dalam kajian ini adalah naratif deskiptif. Maksudnya mendeskripsikan masalah implementasi sinkronisasi waktu yg dihadapi oleh para Penyelenggara Jaringan secara jelas, baik dari sisi regulasi, teknis maupun kondisi lingkungan terkini dan hubungan hubungan yang lain yang ada, sehingga dengan deskripsi itu didapatkan peta permasalahan yang jelas yang kemudian dengan dasar tersebut bisa dikeluarkan rekomendasi kebijakan untuk menyelesaikan permasalahan tersebut.

\section{HASIL DAN PEMBAHASAN}

\subsection{Standar Waktu}

Dalam bentuk besaran fisik, waktu memiliki satuan detik atau sekon. Satu detik didefinisikan berdasarkan keadaan astronomis yang memiliki hubungan dengan perputaran bumi pada porosnya. Kemudian setelah ditemukannya jam atom maka melalui General Conference on Weights and Measures, BIPM (Bureau International des Poids et Mesures ) atau Biro Internasional untuk Timbangan dan Ukuran mendefinisikan unit waktu International System 
(SI) detik berdasarkan waktu atomik, tidak lagi berdasarkan bergerakan bumi [10]. Satu detik adalah 9.192.631.770 kali waktu yang diperlukan untuk peralihan atom cesium 133 pada kondisi bebas medan maknit pada suhu $0^{\circ} \mathrm{K}$. Definisi dalam bahasa Inggris menurut BIPM (www.bipm.org) adalah: The second is the duration of 9192631770 periods of the radiation corresponding to the transition between the two hyperfine levels of the ground state of the caesium 133 atom [11].

\subsubsection{Standar Waktu Internasional}

Saat ini secara global, standar waktu yang digunakan di seluruh dunia saat ini mengacu kepada Universal Time Coordination (UTC). Standard UTC dihasilkan dari hasil kalkulasi jam atom di seluruh dunia dan disesuaikan dengan keadaan astronomis. Sesuai dengan prinsip keakuratan dan ketertelusuran, Jam atom yang dimiliki di seluruh negara biasanya dikelola oleh National Metrology Institute (NMI) negara yang bersangkutan dengan mengacu pada UTC. Demikian halnya untuk Indonesia juga memiliki NMI yang mengelola jam atom, yaitu Pusat Penelitian KIM-LIPI (Kalibrasi, Instrumentasi, dan Metrologi - Lembaga Ilmu Pengetahuan Indonesia).

Jam atom yang dikelola oleh NMI tidak langsung menjadi standar waktu bagi negaranya. Ada proses yang harus dilalui sebelum jam atom tersebut mengikuti standar waktu internasional, UTC. Dari seluruh jam atom yang ada di seluruh dunia akan dihasilkan International Atomic Time (IAT). Standar waktu IAT merupakan hasil kalkulasi BIPM atas dasar pengukuran pada lebih dari 431 standar jam atomik yang dioperasikan oleh NMI and lembaga observatori lainnya di lebih dari 30 negara di seluruh dunia. Hasil perhitungan IAT dapat dilihat pada BIPM Circular $T$ yang dipublikasikan tiap bulan. Kemudian IAT akan ditambahkan dengan leap second dan menghasilkan UTC. Sampai saat ini, telah ditambahkan sebesar 35 detik ke IAT. Jadi beda detik antara UTC dan IAT adalah 35 detik.

Guna menyesuaikan antara jam atomic yang sangat stabil dengan keadaan perputaran bumi yang tidak stabil, maka IAT perlu ditambahkan dengan Leap second. Leap second ini ditambahkan atas rekomendasi dari International Earth Rotation Service (IERS), dengan tujuan untuk menjamin bahwa dalam setahun posisi tertinggi Matahari tidak bergeser lebih dari 0.9 sekon dari pukul 12:00:00 UTC pada garis meredian Greenwich. Dengan demikian UTC merupakan referensi skala waktu yang lebih modern dari Greenwich MeanTime (GMT) yang berbasis astronomis

\subsubsection{Standar dan Zona Waktu Indonesia}

Instansi di Indonesia yang berwenang untuk melakukan standardisasi mengenai waktu adalah Pusat Penelitian KIM LIPI. Sebagai lembaga yang juga berperan sebagai Metrologi Nasional di Indonesia, Puslit KIM LIPI juga mengemban amanat menjamin ketertelusuran pengukuran di Indonesia dan mengelola standar nasional. Dalam hal ini khususnya untuk besaran waktu sebagai bagian dari besaran yang ada di Puslit KIM LIPI. Pengukuran/kalibrasi waktu termasuk didalam ilmu pengukuran dibidang metrologi kelistrikan.

Puslit KIM-LIPI saat ini telah memiliki standar waktu primer yaitu jam atom cesium HP 5071A. Standar waktu ini tertelusur ke standar waktu internasional. Dan realisasi fisik dari UTC di 
Lab. Standar Waktu \& Frekuensi, Puslit KIM LIPI, dinotasikan sebagai UTC(KIM). Terkait dengan zonasi waktu, Indonesia menggunakan (UTC+7) untuk WIB (Waktu Indonesia Barat) yang mencakup pulau Jawa, Sumatera, Kalimantan Barat dan Kalimantan Tengah, UTC+8 untuk WITA (Waktu Indonesia Tengah) yang mencakup seluruh Sulawesi, Kepulauan Sunda Kecil, Kalimantan Utara, Kalimantan Selatan, dan Kalimantan Timur, dan +9 untuk WIT (Waktu

Indonesia Timur) yang mencakup seluruh Maluku dan Papua.

\subsection{Prinsip Ketertelusuran dan Penyedia Jam Acuan serta Server Sinkronisasi Waktu}

Untuk menjamin ketertelusuran UTC (KIM) ke UTC maka dibangun sistem time keeping yang didukung oleh beberapa jam atom cesium dan GPS

Time Transfer System yang mengimplementasikan BIPM All-in View untuk menjamin UTC(KIM) mendekati UTC dalam orde nanosecond seperti pada gambar di bawah ini.

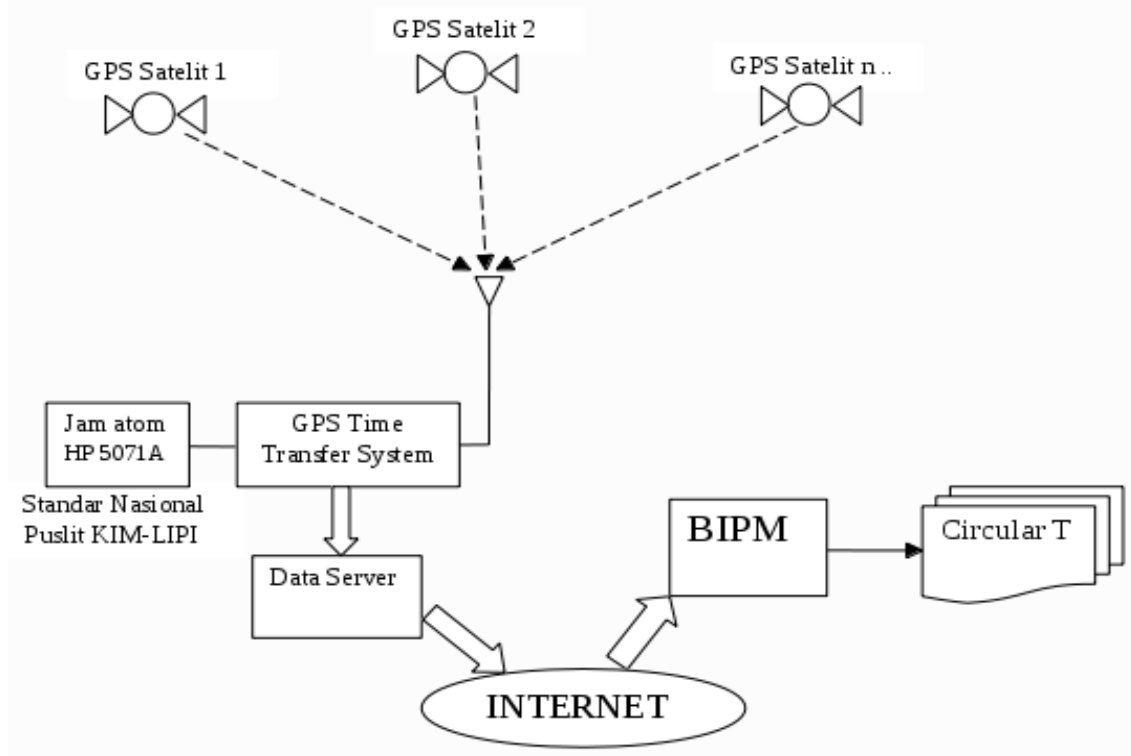

Gambar 2. Sistem Time Keeping Puslit KIM-LIPI

Sumber: BIPM

Sejak 2008, Puslit KIM-LIPI melakukan proses ketertelusuran UTC(KIM) ke UTC menggunakan sistem di atas. Hasil dari proses tersebut diterbitkan oleh BIPM di Circular T. Di Indonesia, penyedia jam acuan untuk waktu di Indoensia adalah NTP Server yaitu kelompok server id.pool.ntp.org. Sementara itu, Penyedia NTP Server Stratum 1 di Indonesia adalah KIMLIPI.

\subsection{NTP Server dan Tingkatannya}

NTP Server atau Time Server dapat berupa komputer biasa yang dijadikan server waktu.
Acuan waktu paling dasar (Stratum 0) yang terhubung ke NTP Server berupa peralatan khusus atau komputer khusus yang bekerja sebagai penyedia waktu acuan, misalnya jam atom. Jam acuan pada Stratum 0 ini tidak tersambung ke jaringan. NTP Server memiliki beberapa tingkatan. Server Stratum 1 saling terhubung melalui jaringan dengan Stratum 1 lainnya dan Stratum 2. Serverserver Stratum 2 juga saling terhubung melalui jaringan, dan terhubung ke Stratum 3, dan seterusnya. 
NTP Server Stratum 1 tersebut terhubung langsung dan tersinkronisasi dengan Server Stratum 0 (jam atom KIM-LIPI). Jika karena suatu dan lain hal sambungan atau sinkronisasi NTP Server Stratum 1 ke Stratum 0 mengalami gangguan, maka NTP Server Stratum 1 harus dapat tersambung / tersinkronisasi dengan NTP Server Stratum 1 lainnya di dunia yang mengacu ke jam acuan dunia (UTC). NTP Server Stratum 2 disediakan oleh penyelenggara jaringan yang terkait komunikasi dan informatika, antara lain:

- Penyelenggara jaringan tetap.

- Penyelenggara jaringan bergerak.

- Penyelenggara jaringan khusus.

NTP Server Stratum 2 harus menjadikan NTP Server Stratum 1 (KIM-LIPI) sebagai acuan utama. Jika karena suatu dan lain hal hubungan NTP Server Stratum 2 dengan NTP Server Stratum 1 (KIM-LIPI) terganggu, NTP Server Stratum 2 harus tersinkronisasi dengan NTP Server 1 atau 2 lainnya yang tersinkronikasi dengan jam acuan dunia (UTC).

Adapun NTP Server Stratum 3 dan di bawahnya ditujukan untuk pengguna akhir dengan penjelasan sebagai berikut.

- Komputer atau perangkat jaringan untuk pengguna akhir yang ditujukan digunakan di Indonesia harus diberikan pilihan default (bawaan) menggunakan sinkronisasi waktu ke jam acuan Indonesia (Stratum 1 KIMLIPI) melalui NTP Server sekunder atau Pool yang disediakan penyedia layanan yang terkait komputer atau perangkat jaringan.

- NTP Server untuk pengguna akhir tersebut berupa kumpulan NTP Server sekunder atau Pool yang berada pada Stratum 3 dan di bawahnya.

- NTP Server Pool (yang berada pada Stratum 3 dan di bawahnya) itu harus mengacu dan tersinkronisasi dengan NTP Server Stratum 2.

- Komputer atau perangkat elektronik pengguna akhir harus mengakses ke Pool (yang berada pada Stratum 3 dan di bawahnya) agar tidak membebani NTP Server di atasnya (Stratum 2) dan tidak direpotkan jika terjadi masalah di NTP Server di atasnya.

- Pemilihan server Pool dan/atau NTP Server sekunder diatur oleh penyedia layanan, misalnya penyedia jasa telekomunikasi, sistem support dari pengembang sistem operasi atau aplikasi, dan sebagainya. Pengguna akhir dapat menyerahkan pemilihan NTP Server untuk peralatannya kepada program yang telah disediakan oleh pembuat komputer, atau perangkat elektronik lainnya, atau pengembang sistem. Dengan demikian pengguna akhir tidak harus mengetahui alamat atau nama NTP server Pool, Stratum 3, Stratum 2, Stratum 1, dan lainlain. 


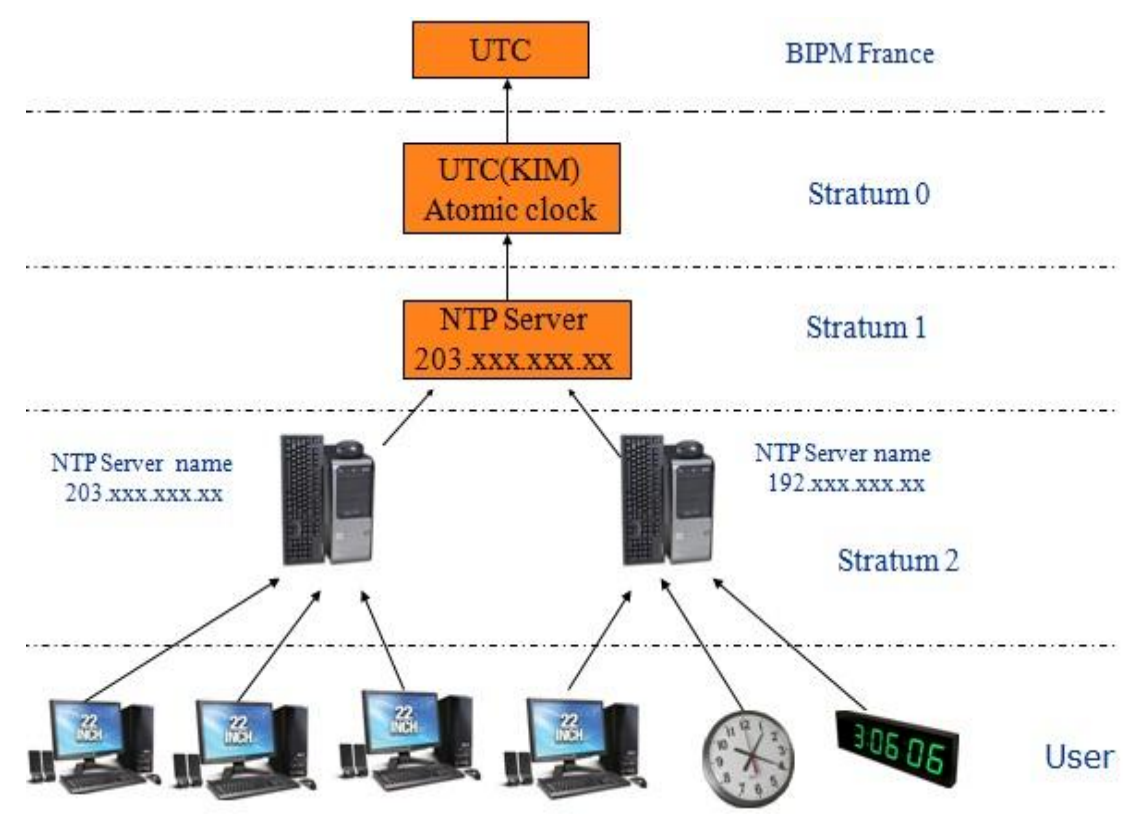

Gambar 3. Hierarki NTP

Sumber : Pusat KIM LIPI

Sesuai informasi yang tersedia di ntp.org, contoh Stratum 1 Time Server adalah ntp.amnic.net. Contoh Stratum 2 Time Server adalah ntp.adc.am. Kedua contoh itu berada di negara Armenia. Sedangkan contoh NTP Pool Time Server adalah pool.ntp.org, asia.pool.ntp.org, europe.pool.ntp.org, dan lain-lain.

\subsection{Sinkronisasi Waktu dengan NTP}

Protokol untuk sinkronisasi waktu berbasis jaringan/internet yang telah menjadi standar saat ini adalah NTP, singkatan dari Network Time Protocol (www.ntp.org), yang dibuat pada 1985. Protokol waktu selain NTP tidak banyak digunakan atau dijadikan acuan di internet, misalnya Time Protocol dan DayTime Protocol, yang keduanya dibuat pada 1983. Tulisan berikut ini menjelaskan apa itu NTP dan bagaimana menggunakannya di komputer dan peralatan bergerak seperti handphone/smartphone dan tablet.

NTP berguna untuk menyamakan atau sinkronisasi waktu komputer atau peralatan elektronik satu dengan yang lain melalui jaringan atau internet. Komputer yang menjadi acuan untuk menyediakan data waktu disebut NTP Server atau Time Server. Komputer atau peralatan lain yang mensinkronkan waktunya kepada NTP Server kita disebut sebagai NTP Client.

Waktu NTP Server dapat mengacu ke NTP Server yang lain. Waktu NTP Server dapat pula mengacu ke waktu perangkat keras yang terhubung ke NTP Server tersebut, misalnya berbasis waktu atom, GPS, atau sinyal lain yang terkait waktu. NTP mendukung zona waktu, misalnya GMT +7 . Format waktu yang digunakan NTP mulai dari 1 Januari 1900, pukul 00:00.00 UTC (Coordinated Universal Time).

Waktu NTP Client, sesuai namanya, mengacu atau mengambil data waktu dari NTP Server. Tidak semua komputer atau peralatan jaringan menggunakan waktu yang disediakan NTP Server atau Time Server lainnya. Misalnya komputer yang tidak terhubung ke jaringan atau internet, biasanya menggunakan waktu yang ada dalam perangkat keras atau chip (CMOS) pada motherboard komputer. Dalam kasus seperti ini, 
komputer tidak menjalankan NTP Client. Demikian pula perangkat bergerak seperti handphone dapat diset menggunakan waktu jaringan maupun waktu secara manual (internal clock).

\subsection{Mengukur Ketelitian NTP dengan}

\section{Menghitung Estimasi Network Delay}

Untuk mendeteksi perbedaan waktu antara satu sisi dengan sisi lainnya, NTP mengasumsikan bahwa incoming delay sama dengan outgoing delay. Tapi sebenarnya, ketika congestion terjadi, kedua hal tersebut tidaklah sama. Maka akan digunakan beberapa clocks untuk mengurangi kesalahan. Paket-paket NTP akan saling bertukan antara server dan client dengan interval waktu berkisar dari 1 sampai 12 menit untuk mengukur perbedaan waktu. Paket-paket ini akan memberi tahu tentang incoming dan outgoing delay jika clock-clock ini telah tersinkronisasi secara sempurna. Tapi ketika hanya satu sisi dari NTP server dan client yang tersedia dan sisi tersebut tidak dapat dibuktikan telah tersinkronisasi waktu (time synchronized), kita tidak dapat mengukur incoming dan outgoing delay secara tepat. Untuk menjaga kepresisian clock, dibutuhkan mempersiapkan sisi (pair) sebanyak mungkin.

Baik dalam metode pengukuran delay dan juga estimasi, digunakan algoritma Marzullo. Algirtma tersebut diciptakan oleh Keith Marzullo pada tahun 1984, yang digunakan untuk memilih sumber dalam memperkirakan waktu yang akurat dari sejumlah sumber waktu berisik. Sebuah versi halus itu, berganti nama menjadi "algoritma persimpangan", merupakan bagian dari modern Network Time Protocol. Algoritma Marzullo ini juga digunakan untuk menghitung persimpangan santai kotak $\mathrm{n}$ (atau lebih umum himpunan $\mathrm{n}$ bagian dari $\mathrm{R}^{\mathrm{n}}$ ), seperti yang dipersyaratkan oleh beberapa metode estimasi set kuat. Algoritma Marzullo juga digunakan dalam menghitung efisien dalam hal waktu untuk menghasilkan nilai optimal dari serangkaian perkiraan dengan interval kepercayaan dimana nilai sebenarnya mungkin di luar interval kepercayaan untuk beberapa sumber. Dalam hal ini estimasi terbaik diambil untuk menjadi interval terkecil konsisten dengan jumlah terbesar dari sumber [12].

Dalam kasus ini, rute antara $\mathrm{X}$ dan $\mathrm{Y}$ telah dioverlap oleh rute dari X ke A dan X ke C. Delay yang terjadi dari $\mathrm{X}$ ke $\mathrm{A}$ adalah jumlah dari delay yang terjadi dari $\mathrm{X}$ ke $\mathrm{Y}$ dan delay yang terjadi dari Y ke A. Kita juga dapat memisahkan langkah dari $\mathrm{X}$ ke B menjadi langkah dari X ke Y dan langkah dari Y ke B. Ketika delay dari X ke Y berubah karena beberapa sebab, akan mempengaruhi delay dari X ke A dan dari X ke B. Di sisi lain ketika delay dari $\mathrm{Y}$ ke $\mathrm{A}$ berubah, delay dari $\mathrm{X}$ ke $\mathrm{A}$ berubah, sementara delay dari $X$ ke $B$ tidak berubah. Maka kita dapat memisahkan delay dari X ke $\mathrm{Y}$ dari delay dari $\mathrm{Y}$ ke A.

Ketika pergerakan delay dari $\mathrm{X}$ ke $\mathrm{A}$ serupa dengan pergerakan delay dari X ke B, kita dapat menganggap pergerakan delay datang dari delay yang berasal dari X ke Y. Ketika tidak mirip, kita dapat menganggap pergerakan delay datang dari pergerakan delay yang sebenarnya dari masing-masing $\mathrm{Y}$ ke A dan dari Y ke B.

\subsubsection{Metode Pengukuran Delay}

Dengan memasang clock server dengan antena GPS di sisi client dan clock client di sisi server, maka akan didapatkan statistik jaringan yang menggunakan server NTP ini. Server NTP akan menemukan server NTP lainnya. Maka hal 
tersebut sudah membuat sebuah collector untuk delay satu-arah. Dengan demikian hal tersebut sudah dapat diguanakan untuk menemukan delay per bagian dari jaringan dari informasi delay pada server-server NTP.

\subsubsection{Metode Estimasi}

Berdasarkan contoh kasus tersebut diatas, dapat diformalkan metode untuk estimasi sebagaimana dijelaskan sebagai berikut; Pertama, waktu ketika delay ditemukan ditunjukkan dengan t. Waktu awal ditunjukkan dengan S, waktu akhir dengan E. Maka $\mathrm{S}<\mathrm{t}<\mathrm{E}$. Kita menunjukkan delay satu-arah dengan $\mathrm{d}(\mathrm{t})$, delay satu-arah dari $\mathrm{P}$ ke $\mathrm{Q}$ sebagai d $\mathrm{P}->\mathrm{Q}(\mathrm{t})$.

Kita mengestimasikan delay satu-arah antara $\mathrm{P}$ dan $\mathrm{Q}$ sebagai perbedaan waktu yang tampak antara server NTP dan round-trip delay diantara mereka. Sebagai contoh delay satu-arah yang ditunjukkan dengan $\mathrm{d}(\mathrm{t})$ dapat didapatkan dari penjumlahan setengah dari round-trip delay dan perbedaan waktu yang tampak dari server NTP. Karena round-trip delay dan perbedaan dari waktu observasi adalah:

$$
\text { d P->Q + d Q->P, d P->Q - d Q->P }
$$

Perhatikan delay satu-arah dari outgoing atau incoming paket. Pada lingkungan kerja kita, delay satu-arah dibagi menjadi dua komponen. $\mathrm{da}(\mathrm{t})$ yang berhubungan dengan waktu dan dd yang tidak berhubungan dengan waktu.

Berdasarkan lingkungan kerja ini, diformulkan bagaimana menghitung delay dari $\mathrm{X}$ ke Y menggunakan delay data dari $X$ ke $A$ Selanjutnya ditunjukkan delay satu-arah dari $\mathrm{X}$ ke A, dan dari X ke B sebagai d X->A(t), d X->B(t), komponen variabel waktu mereka sebagai da X-
$>\mathrm{A}(\mathrm{t}), \mathrm{db} \mathrm{X}->\mathrm{B}(\mathrm{t})$ dan komponen time-constant masing-masing sebagai dd X->A, dd X->B . Lalu, jika perbedaan antara da $\mathrm{X}->\mathrm{A}(\mathrm{t})$ dan da $\mathrm{X}->\mathrm{B}(\mathrm{t})$ sedikit, kita tahu bahwa d X->A(t) mirip dengan d $\mathrm{X}->\mathrm{B}(\mathrm{t})$. Kita mengasumsikan bahwa nilai minimum dari komponen time-constant dari $\mathrm{d} \mathrm{X}$ $>\mathrm{A}(\mathrm{t}), \mathrm{d} \mathrm{X}->\mathrm{B}(\mathrm{t})$ telah diperkirakan secara baik dari komponen time-constant dari d X-> Y(t). Selanjutnya kita mengasumsikan komponen variabel waktu d X->A(t) dan $\mathrm{d} X->\mathrm{B}(\mathrm{t})$ memiliki karakteristik yang mirip ketika perbedaaan dari komponen variabel waktu bernilai kecil. Ini berarti da $\mathrm{X}->\mathrm{A}(\mathrm{t})$ dan da $\mathrm{X}->\mathrm{B}(\mathrm{t})$ memiliki nilai yang mirip dengan $\mathrm{X}->\mathrm{A}$ dan $\mathrm{X}->\mathrm{B}$.

Kita mengasumsikan kemiripan nilai dapat memperkirakan dengan baik komponen variabel waktu dari elemen X->Y. Lalu kita menggunakan rata-rata elemen variabel waktu dari X->A dan X>B sebagai komponen variabel waktu delay dari X -> Y. Ketika perbedaan antara da X->A(t) dan da $\mathrm{X}->\mathrm{B}(\mathrm{t})$ kecil, kita dapat menunjukkan persamaan berikut tentang perkiraan delay antara $\mathrm{X}$ dan $\mathrm{Y}$ dapat kita pegang.

Dalam kasus ini, kita tahu bahwa delay dari $\mathrm{X}$ ke $\mathrm{Y}$ menggunakan data delay dari $\mathrm{X}$ ke $\mathrm{A}$, dan dari X ke B. Tapi jika terdapat perbedaan yang besar antara da $\mathrm{X}->\mathrm{A}(\mathrm{t})$ dan da $\mathrm{X}->\mathrm{B}(\mathrm{t})$, metode ini tidak dapat digunakan. Ketika terdapat perbedaan yang besar, kita dapat mengestimasikan nilai dari komponen $\mathrm{Y}->\mathrm{A}$ dan $\mathrm{Y}->\mathrm{B}$ jauh lebih besar dari elemen X->Y pada X->A dan X->B. Jadi, pada kasus ini, tidak dihitung delay dari $\mathrm{X}->\mathrm{Y}$ dengan presisi. Untuk kasus ini, perlu dipersiapkan C, D. Ketika terdapat perbedaan yang besar da $X->A(t)$ dan da $\mathrm{X}->\mathrm{B}(\mathrm{t})$, kita mengasumsikan delay dari Y$>$ A dapat diperkirakan sebagai $\mathrm{d} Y->\mathrm{A}(\mathrm{t})=\mathrm{d} \mathrm{X}-$ $>\mathrm{A}(\mathrm{t})-\mathrm{d} \mathrm{X}->\mathrm{Y}(\mathrm{t})$ 


\subsection{Pengaturan di Perangkat Pengguna Akhir}

\section{dan Perangkat Bergerak}

Komputer (server, desktop, laptop, netbook, dan sebagainya) atau perangkat elektronik lainnya untuk pengguna akhir (end-user) yang terhubung ke jaringan harus dikonfigurasi secara default (bawaan)

oleh pembuat/pengembang/penyedia layanan untuk menggunakan sinkronisasi waktu Server NTP yang disediakan oleh penyedia layanan elektronik seperti dijelaskan pada bab sebelumnya. Zona waktu harus menggunakan salah satu dari tiga yang digunakan Indonesia saat ini, yakni WIB, WITA, WIT (dalam bahasa Indonesia) atau IWT, ICT, IET (dalam bahasa Inggris). Penulisan zona waktu Indonesia dalam singkatan bahasa Inggris adalah sebagai berikut:

1. IWT (Indonesia Western Time) untuk UTC+7 yang mencakup pulau Jawa, Sumatera, Kalimantan Barat dan Kalimantan Tengah

2. ICT (Indonesia Center Time) untuk UTC+8 yang mencakup seluruh Sulawesi, Kepulauan Sunda Kecil, Kalimantan Utara, Kalimantan Selatan, dan Kalimantan Timur,

3. IET (Indonesia Eastern Time) untuk UTC+9 yang mencakup seluruh Maluku dan Papua.

Pengguna komputer (server, desktop, laptop, netbook, dan sebagainya) atau perangkat jaringan lainnya untuk pengguna akhir tidak dituntut harus mengetahui alamat-alamat server NTP, karena pengembang sistem operasi atau aplikasi sudah menyediakan program bantu dan sekaligus memilihkan beberapa server, seperti contoh pada sistem operasi Linux Ubuntu dan turunannya berikut ini.

Misalnya, jika kita menggunakan Linux Ubuntu atau turunannya seperti BlankOn 7 atau Mint 13, maka secara default Linux-Linux itu menggunakan salah satu dari beberapa server yang telah dipilih dalam konfigurasi NTP Client. Berikut ini contoh daftar NTP server pool yang dipilih Linux Mint 13 secara default. Jika akan digunakan di Indonesia, konfigurasi default di bawah ini harus dipastikan tersinkronisasi dengan NTP Server Stratum 2 yang ada disediakan penyedia jasa di Indonesia, atau diubah menjadi nama-nama server NTP pool yang disediakan di Indonesia.

- $\quad$ 0.ubuntu.pool.ntp.org

- 1.ubuntu.pool.ntp.org

- 2.ubuntu.pool.ntp.org

- 3.ubuntu.pool.ntp.org

- ntp.ubuntu.com

Pengguna hanya perlu mengetahui cara menggunakan program pengatur waktu (Time \& Date), untuk memilih pengaturan waktu secara manual (tidak mengacu ke NTP Server) atau otomatis (mengacu ke NTP Server).

Pada perangkat bergerak (mobile devices), setup waktu jaringan pada peralatan elektronik ini biasanya diberi nama (pilihan setup waktu) "Automatic" atau "Use network-provided values" atau istilah lain yang maknanya serupa. Artinya nilai jam menggunakan jam yang disediakan oleh server waktu milik penyedia jaringan, yang tersinkronisasi dengan waktu acuan Indonesia. Sedangkan pilihan waktu yang tidak otomatis atau tidak menggunakan waktu jaringan biasanya diberi nama "Manual" atau mematikan (un-check) pilihan Automatic, sehingga tidak tersinkronisasi dengan 
waktu acuan. Perangkat elektronik untuk Pengguna Akhir (end-user) yang terhubung ke jaringan harus terkonfigurasi secara default (bawaan) oleh pembuat/pengembang/penyedia perangkat keras dan perangkat lunak yang digunakan untuk menselaraskan waktu server Network Time Protocol Stratum 3.

\subsection{Implementasi Sinkronisasi Waktu}

Implementasi sinkronisasi waktu bagi penyelenggara jasa telekomunikasi telah diatur pada PP 52/2000 Pasal 89 yang mengatur mengenai perekaman informasi harus memuat masa rekaman dan periode waktu. Selain itu juga diatur pada Peraturan Dirjen Pos da Telekomunikasi No 251 tahun 2011 tentang Penyelarasan Waktu. Aturan teknis mengenai sinkronisasi waktu juga merujuk pada standard Internasional; ISO 8601, RFC 5905, RFC 1305. Secara teknis, seluruh perangkat jaringan Operator, NAP, IXP dan ISP wajib melakukan sinkronisasi waktu ke NTP server yang ditentukan oleh Direktur Jenderal Pos dan Telekomunikasi yaitu kelompok server id.pool.ntp.org. Operator, NAP, IXP dan ISP menyediakan server NTP untuk keperluan sinkronisasi waktu bagi seluruh perangkat jaringan yang berada di bawahnya (hingga tingkat pelanggan akhir) dan mewajibkannya. Sedang wilayah waktu menyesuaikan GMT yaitu GMT +7 untuk Waktu Indonesia Bagian Barat, GMT +6 untuk Waktu Indonesia Bagian Tengah dan GMT +5 untuk Waktu Indonesia Bagian Timur.

Setiap Operator, NAP, IXP dan ISP wajib mencantumkan sejumlah ketentuan dalam perjanjian kerja sama dengan pelanggan dan atau dalam Klausul Persetujuan Pelanggan (Acceptance
User Policy - AUP) pengguna di bawahnya seperti berikut:

1. Kewajiban melakukan sinkronisasi waktu perangkat jaringan dan terminal akses ke NTP server yang telah ditunjuk yaitu kelompok server id.pool.ntp.org;

2. Bagi pelanggan yang memiliki jaringan pengguna tertutup sendiri (private, closed user group) dan memiliki banyak pengguna serta tersebar, wajib melakukan perekaman transaksi koneksi (log) sendiri;

3. Bagi pelanggan yang memiliki jaringan pengguna tertutup sendiri (private, closed user group) dan memiliki banyak pengguna serta tersebar, wajib melakukan pendataan identitas pengguna layanannya;

4. Bagi saluran distribusi (seperti HotSpot dan Warnet) wajib menerapkan mekanisme otentikasi dan atau pendataan identitas pengguna.

Sanksi administratif dan teknis juga harus dicantumkan dalam setiap perjanjian kerja sama / Klausul Persetujuan Pelanggan sebagai berikut:

1. Penolakan dan atau pelanggaran terhadap kewajiban di atas dikenakan sanksi administrasi berupa teguran dan peringatan;

2. Penolakan dan atau pelanggaran terhadap kewajiban di atas dikenakan sanksi teknis berupa pemblokiran alamat Internet;

3. Bila sanksi administrasi dan teknis tidak diindahkan, maka kepada pengguna ybs. akan dikenakan pemutusan akses sementara;

4. Pemutusan akses (koneksi) dan pembatalan PKS untuk seterusnya. 
Metode implementasi yang paling aman dan paling dapat diandalkan metode untuk mensinkronisasikan semua jam pada jaringan telekomunikasi adalah dengan waktu khusus server menjalankan NTP atau SNTP (Simple Network time Protocol):

1. Instalasi server waktu jaringan di belakang firewall dan isolasi dari Internet untuk menyediakan keamanan yang terbaik.

2. Anda menghindari pekerjaan tambahan reconfiguring firewall dan router yang mungkin diperlukan untuk memungkinkan perangkat pada akses LAN Anda ke Internet Publik Waktu Server.

3. Karena latency yang minimal, server waktu jaringan di LAN Anda dipercaya bisa menyimpan semua server,

Untuk mengakses Internet Time Server menggunakan NTP, masalah muncul karena sumber waktu di luar firewall. Ini berarti harus ada "hole" (lubang/celah) yang dibiarkan terbuka di firewall (khusus UDP port 123) untuk memungkinkan paket yang berisi informasi waktu. Lubang keamanan adalah masalah utama dengan mendapatkan waktu dari Internet. Ketepatan waktu degradasi ketika menggunakan Internet Time Server karena latency asimetris. Penundaan antara ketika paket saat meninggalkan sumber waktu dan ketika mereka tiba di jaringan.

Penyelenggara Jaringan Telekomunikasi Tetap, Penyelenggara Jaringan Telekomunikasi Bergerak dan Lembaga Penyiaran Penyelenggara Penyiaran Multipleksing dapat menyediakan pemilihan server Pool dan/atau NTP Server sekunder yang diatur oleh penyedia layanan dengan format sebagai berikut: [nomor_pool].[nama_layanan].pool.nt

p.org

Penyelenggara Jaringan Telekomunikasi

Tetap, Penyelenggara Jaringan Telekomunikasi Bergerak dan Lembaga Penyiaran Penyelenggara Penyiaran Multipleksing wajib melaksanakan penyelarasan waktu sebagaimana yang dimaksudkan dalam Peraturan Menteri ini melalui Uji Layak Operasi (ULO). Penyelenggara Jaringan Telekomunikasi Tetap, Penyelenggara Jaringan Telekomunikasi Bergerak dan Lembaga Penyiaran Penyelenggara Penyiaran Multipleksing wajib memiliki server Network Time Protocol yang terhubung melalui jaringan Stratum 2. Penyelenggara Jaringan Telekomunikasi Tetap, Penyelenggara Jaringan Telekomunikasi Bergerak dan Lembaga Penyiaran Penyelenggara Penyiaran Multipleksing wajib menyediakan Time Server Stratum 3 untuk kebutuhan Pengguna Akhir.

\section{PENUTUP}

Berdasarkan hasil pembahasan dalam kajian ini, dapat disimpulkan sebagai berikut:

NTP merupakan protokol yang penting bagi penyelenggara jasa telekomunikasi karena mengatur jam untuk berjuta host. NTP adalah metode klasik sinkronisasi waktu bagi seluruh perangkat komputasi dan jaringan. Standar NTP memungkinkan sinkronisasi waktu secara tepat dan presisi, dengan perangkat-perangkat yang sudah umum digunakan seperti komputer dan telepon pintar atau smartphone. Sistem tersebut sudah memperhitungkan delay dalam proses transmisi, sehingga ketepatannya dapat dijamin di mana pun 
ada koneksi ke jaringan internet. NTP juga dapat memberikan akurasi waktu di urutan 10s milidetik, yang mungkin cukup untuk notifikasi seperti SMTP atau syslog, tapi biasanya tidak cukup untuk memantau layanan jaringan sensitif terhadap waktu atau aplikasi. Oleh karena itu, dibutuhkan standardisasi waktu yang mengacu pada Universal time Coordination (UTC). Standard UTC dihasilkan dari hasil kalkulasi jam atom di seluruh dunia dan kemudia disesuaikan sesuai dengan astronomis dengan prinsip ketertelusuran. Lembaga yang berwenang untuk mengelola standard dan sinkronisiasi waktu pada stratum 1 dan merupakan acuan utama di Indonesia.

Berdasarkan hasil kajian dan kesimpulan yang telah diuraikan, disampaikan beberapa saran sebagai berikut :

Penyelenggara Jasa Telekomunikasi dan Lembaga Penyiaran Penyelenggara Program Siaran yang bertujuan menyediakan transaksi elektronik wajib memiliki server Network Time Protocol yang menggunakan server Network Time Protocol yang terhubung melalui jaringan Network Time Protocol Stratum 2. Standar waktu yang digunakan mengacu kepada Coordinated Universal Time (UTC). Pembuat/pengembang/vendor perangkat keras dan perangkat lunak untuk penyelenggara system elektronik wajib menyediakan pengaturan otomatis dan menyediakan pemilihan beberapa Time Server yang terdapat dalam daftar Sistem Penyelarasan Waktu Indonesia. Selain itu, Pembuat/pengembang/vendor perangkat keras dan perangkat lunak tersebut juga wajib menyediakan panduan untuk melakukan konfigurasi secara manual.

Untuk Perangkat elektronik untuk Pengguna Akhir (end-user) yang terhubung ke jaringan, jika perangkat elektronik belum terkonfigurasi secara otomatis (default), maka pengguna harus melakukan sesuai dengan cara yang terdapat pada buku manual atau mengikuti panduan pengaturan penselarasan waktu

\section{UCAPAN TERIMA KASIH}

Saya mengucapkan terima kasih kepada Kapuslitbang PPI, Dr. Hedi M Idris, M.Sc, mitra bestari yang telah memberi koreksi dan masukan, rekan-rekan Peneliti di Puslitbang PPI dan Puslitbang APTIKA dan IKP atas dukungannya sehingga dapat terselesaikannya kajian literatur sinkronisasi waktu dengan network time protocol untuk pemantauan aktivitas jaringan telekomunikasi.

\section{DAFTAR PUSTAKA}

Direktorat Jenderal Pos Dan

Telekomunikasi, Departemen Komunikasi dan Informatika, Peraturan Menteri Kominfo Nomor 27/PER/M.KOMINFO/9/2006 Tentang Pengamanan Pemanfaatan Jaringan

Telekomunikasi Berbasis Protokol Internet. Jakarta, 2006

Direktorat Jenderal Aplikasi

Telematika, Undang-Undang No. 11 Tahun 2008 tentang Informasi dan Transaksi Elektronik (UU ITE), Jakarta 2008

Direktorat Jenderal Aplikasi

Informatika, Kementerian Kominfo, Peraturan Pemerintah No 82 Tahun 2012 tentang Penyelenggara Sistem Transaksi Elektronik (PP PSTE), Jakarta, 2012 
Ganeriwal, S., Capkun, S., Han, C., Srivastava, B. M., Secure Time Synchronization Service for Sensor Networks. In Proceedings of ACM conference on WiSE, Cologne, Germany, September, 2005.

Elson, J., Girod, L., Estrin D.. Finegrained network time synchronization using reference broadcasts. In Proceedings of the Fifth Symposium on Operating Systems Design and Implementation (OSDI), Boston, MA, December 2002.

Ganeriwal, S., Kumar, R., Srivastava, M. B.. Timing-sync protocol for sensor networks. In Proceedings of the First ACM Conference on Embedded Networked Sensor Systems (SenSys),Los Angeles, CA, November 2003.

Maroti, M., Kusy, B., Simon, G., Ledeczi, A.. The flooding time synchronization protocol. In Proceedings of the Second ACM Conference on Embedded Networked Sensor Systems (SenSys), November 2004.
Greumen. J. V., Rabaey, J.. Lightweight time synchronization for sensor networks. In Proceedings of the Second ACM International Workshop on Wireless Sensor Networks and Applications (WSNA),San Diego, CA, 2003.

Sichitiu, M. L., Veerarittiphan, C.. Simple, accurate time synchronization for wireless sensor networks. In Proceedings of the IEEE Wireless Communications and Networking Conference (WCNC), 2003.

Pusat Penelitian Metrologi LIPI, http://www.kim.lipi.go.id

Bereau Internasionales des Pods et Mesures, Time scales, http://www.bipm.org/en/bipm$\underline{\text { services/timescales/ }}$

K. A. Marzullo. Maintaining the Time in a Distributed System: An Example of a Loosely-Coupled Distributed Service. Ph.D. dissertation, Stanford University, Department of Electrical Engineering, February 1984. 